\title{
When Trees Dream of Being Trees
}

The tree decided to stop growing after it grew its thousandth leaf. "No more," it whispered, and started throwing flimsily attached twigs and old nests down, and shaking the birds out. "I am a terrible tree! A thousand leaves is more than enough to prove that! I am slow and slight and my leaves are not lustrous. I have never made a flower, never made an apricot, never made an acorn. Go away birds! I am an impostor tree! I will be a post, if I can just shake off these redundant branches," and the tree bounced up and down, twirled violently, and tried some catapulting maneuvers in an effort to fling off its limbs. Nothing much was flung, except for some leaves and a butterfly, and they were instantly free from its flinging force, and ended up drifting away instead of zinging through the air. And so the tree started to slam itself against the earth. Its branches were most certainly broken this way, but they were not broken off: such fibrous material does not easily come loose, does not easily separate from itself. So the tree was hung with broken creaking branches. Aghast, it felt itself growing. And, knowing it would only grow more of itself, it cried, "I must get out of the sunlight! I must get out of the rain!" It tried to sink into the dirt. But trees with their spreading root systems are even harder to push down into the dirt than they are to pull up. So the tree finally just stood there with its smashed branches, exhausted, in the late afternoon sunlight. The other trees around regarded the tree going mad without much comment. They had seen this dreadful thing happen before, when trees dream of being trees. 